\title{
Supporting language learning on the move: An evaluative framework for mobile language learning resources
}

\author{
Hayo Reinders, Unitec \\ $\&$ \\ Mark Pegrum, The University of Western Australia
}

\begin{abstract}
Mobile learning is becoming increasingly common, and mobile learning resources for supporting the teaching and learning of language are now widely available (Pegrum, 2014). There is, however, little systematic research into their benefits, with most publications reporting case studies of pilots or trials, and data largely consisting of learners' and teachers' perceptions (Burston, 2013). As useful as these studies are, they do not necessarily help teachers to identify those aspects of mobile resources that can make a significant pedagogical contribution in particular learning contexts.

This chapter presents a framework for evaluating mobile-assisted language learning (MALL) resources, which may take the form of web services or apps (or collections of websites or apps), referred to here as mobile materials; or which may take the form of activities designed around websites or apps, referred to here as mobile activities. In both cases, the websites and apps may either have a dedicated language learning focus or be generic in nature.

After a discussion of the nature of mobile hardware and software, we consider the evaluation of MALL resources, which in fact means an evaluation of the learning design of those resources. We present five categories according to which their learning design may be evaluated, namely the use of the affordances of the devices, general pedagogical approaches, specific L2 pedagogical approaches, second language acquisition (SLA) principles, and affective principles. We synthesise these points into an evaluative framework that can be used by practitioners to appraise particular MALL resources or even guide their own production of such resources.
\end{abstract}

\section{Introduction}

A number of important developments of direct relevance to mobile learning took place in 2013. In that year, the number of internet-enabled mobile devices worldwide surpassed the number of desktop and laptop computers (The Economist, 2012); sales of smartphones surpassed sales of feature phones (Blodget et al., 2013); and mobile-generated traffic reached $20 \%$ of all internet traffic (ibid.), before increasing to more than 25\% in the first half of 2014 (Meeker \& Wu, 2014). It is timely for teachers and researchers to seek to identify and capitalise on the educational potential of these developments.

There is some disagreement over exactly what constitutes a 'mobile' as opposed to a 'portable' device, but Ruben Puentedura (2012) suggests a rule of thumb by which the latter is a device which is typically used at Point A, closed down and transported, then opened up again at Point B; while the former is a device that can be used at Point A, Point B and everywhere in between without stopping. From this 
perspective, today's most common mobile devices include mobile phones or cellphones (both feature phones and smartphones, with the latter running on mobile operating systems and being largely appdriven) and tablets. Older mobile devices, which are becoming less common as their functionality is subsumed into smartphones and tablets, include personal digital assistants (PDAs) and MP3 players. Newer mobile devices which are beginning to emerge include wearables such as fitness trackers (often in the form of wrist bands), smartwatches and smart glasses (or augmented reality glasses). While laptops, especially smaller notebooks and netbooks, share some similarities with mobile devices, they in fact fall into Puentedura's portable category.

Smart mobile devices have a range of input mechanisms, thanks to the move towards natural user interfaces which can be operated by touch, gesture and voice. These devices also allow optical recognition of text, quick response $(\mathrm{QR})$ codes and other augmented reality (AR) markers; they are location-aware, thanks to inbuilt GPS receivers, compasses, gyroscopes and accelerometers; and they can pick up signals from Bluetooth, radio frequency identification (RFID) and NFC (near field communication) tags. Output modes include the visual, auditory and haptic (that is, tactile output, such as the vibration of a phone).

There are two main ways to engage in learning with a mobile device. The first involves using a general web browser to access websites, some of which may have been optimised for mobile access; the second involves downloading dedicated, single-purpose pieces of software called apps, which are normally sourced from online app stores. Apps provide a smoother, more streamlined experience, with most social media platforms and many educational services offering app versions, and increasing numbers adopting an app-first or app-only approach. At the same time, however, end users often find themselves with less control over their online experience than on the wider web 2.0, and with far less ability to move easily between apps, which effectively operate as walled gardens isolated from each other and the wider web (Pegrum, 2014). Some educators worry that the kind of active, collaborative learning facilitated by web 2.0 is being eroded by a slick, corporatized 'appification' of the web (Quitney Anderson \& Rainie, 2012), leading to a learning landscape populated by individually purchased, independently used, standalone apps training limited sets of knowledge or skills.

There are two categories of mobile resources (whether general m-learning or specific MALL resources) available to teachers and students. Firstly, there are mobile materials, in the form of web services or apps (or collections of websites or apps); and secondly, there are mobile activities, in the form of activities designed around websites or apps (see Table 1).

Mobile materials include dedicated web services and apps that are content-specific and don't require adaptation for language learning. In many cases, not only the content but often the pedagogy has already been designed into these sites and apps. Particularly in the case of apps, the pedagogy tends to be somewhat traditional, leaning towards information transmission and especially behaviourism (Murray \& Olcese, 2011; Oakley et al., 2012; Searson, 2014; UNESCO, 2012). As with m-learning in general, the vast majority of available MALL materials are underpinned by "a behaviorist, teacher-centred, transmission model of instruction" despite the potential for "more innovative constructivist, collaborative, learner-centred instruction” (Burston, 2014, p.344; cf. Beatty, 2013).

Some more recent apps are overlaid with social networking and sharing channels which offer more active learning options, and simple app design is now coming within the reach of teachers and students 
thanks to the availability of easy-to-use app-building software (Miller \& Doering, 2014), thus increasing the collaborative, constructivist potential. While dedicated language learning materials can be used in a standalone manner, they can of course also be incorporated into the design of broader mobile activities for language learning, which may have a more collaborative and/or constructivist orientation. Thus, a pedagogically limited information transmission app (say, an online dictionary) or a behaviourist app (say, a set of grammar drills) might form part of a larger collection or activity underpinned by a more sophisticated pedagogical design. Generic materials, like social networking services and videosharing sites, also offer many possibilities for active, collaborative learning, though they need to be adapted to different content areas (such as language learning) and their pedagogical use needs to be carefully considered in the overall design of a learning activity. Such learning activities may involve either a fully digital approach, or a blended approach where digital resources are combined with analogue materials in a face-to-face context.

Table 1: Classification of Mobile Learning Resources

Mobile Materials

Dedicated

Generic

Mobile Activities

Dedicated
Web-based

Dedicated web services

Generic web services
App-based

Dedicated apps

Generic apps

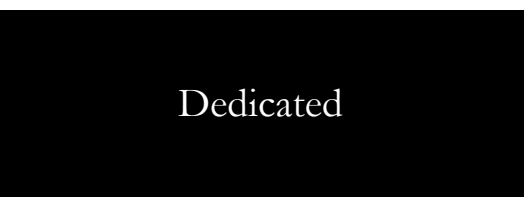

May use any combination of dedicated and/or generic web services and/or apps within the design of a broader learning activity. If only generic web services and/or apps are used, they must be incorporated within the broader design of a learning activity, which may be a fully digital or blended activity.

Given the disjuncture between the promising future potential and the disappointing current reality of m-learning and MALL, it is important that educators have an evaluative framework which can guide them in assessing the benefits of the mobile resources they are considering using with their students, as well as guiding them in the design of mobile resources they may create themselves.

\section{Evaluating MALL resources}

The evaluation of MALL resources ultimately comes down to an evaluation of the learning design of those resources. It has been noted in recent years that, with the increasing rollout of technology, there is a growing emphasis on the importance of learning design (Phillips, McNaught \& Kennedy, 2012), with teachers increasingly being required to adopt the role of learning designers (Garcia, 2014; Hockly, 2013; Laurillard, 2012; Miller \& Doering, 2014; Milrad et al., 2013). While it is true that the nature of the available access to hardware, software and connectivity, as well as various aspects of the hardware and software itself (such as input and output mechanisms with the former, or customization options with 
the latter), have an impact on the learning that is possible, these elements fall outside the area of learning design and are not considered here, although we will return to them in our conclusion.

The learning design can be evaluated with respect to a number of categories: the extent to which the potential educational affordances of mobile devices are exploited in the learning design (see Category 1 in our framework); the extent to which the learning design corresponds to general pedagogical approaches (Category 2); the extent to which the learning design corresponds to specific L2 pedagogical approaches (Category 3); the extent to which the learning design corresponds to SLA principles (Category 4); and, finally, the extent to which the learning design takes into account affective principles (Category 5). While the measurement of learning outcomes is an important consideration in the implementation of MALL or indeed any learning resources, this is only possible post-implementation. Thus, while it may impact on subsequent reuse or redesign, it cannot influence initial use or design, and is therefore not considered here.

Category 1: Affordances. All technologies have their own particular affordances, that is, uses to which they seem to most readily lend themselves. For Klopfer, Squire, Holland, and Jenkins (2002), the key affordances are portability (which may allow distributed learning, for example), social interactivity (which may promote comprehensible input and output), context sensitivity (which may support situated learning), connectivity (which may foster networked learning), and individuality (which may encourage autonomous learning) (cf. also Klopfer \& Squire, 2008). In a more recent perspective which partly echoes Klopfer et al. (2002), Dennen and Hao (2014) list the key affordances of mobile technologies as portability, connectivity, input devices and sensors (which may promote personalized learning and situated learning, as well as allowing more detailed and diverse feedback), and recording abilities (which may support situated and immersive learning).

Pegrum (2014) has suggested that mobile devices have at least three major sets of affordances which are relevant to learning, and which subsume many of the elements described in earlier accounts. Firstly, they allow a linking of the local and the global: we interact in and with our local environments while simultaneously remaining connected to global networks of resources and people, from whom we can learn about our local contexts and with whom we can share learning generated in our local contexts (thus, for example, there is support for distributed learning, situated learning and networked learning). Secondly, they allow a linking of the episodic and the extended: we can engage in bite-sized learning whenever and wherever we find ourselves with moments of downtime, but we can connect those bite-sized chunks into extended learning by simply taking up our learning where we left it off the next time a free moment arises (thus, amongst other things, there is support for autonomous learning). Thirdly, they allow a linking of the personal and the social: we make individual choices about our hardware and our software and can tailor our learning journeys to our own needs and preferences, but we can also hook into global networks and learning communities anytime and anywhere we please (again, there is support for autonomous and networked learning, as well as for specific SLA principles such as comprehensible input and output).

It is also important to consider the level of mobility of the devices. At the most basic level, only the devices are mobile while the learners and the learning experience are not, for example in a connected classroom where students use a class set of tablets while sitting at their desks. At a more sophisticated level, the learners also become mobile, for instance when they move around or between learning spaces to share their learning with peers; while such student mobility may foster collaboration and creativity, the learning experience itself is not mobile in that it could take place in any space or spaces, and remains unaltered by 
those spaces. At a still more sophisticated level, the learning experience itself becomes mobile as the changing environment feeds into and alters the learning process, for example as students make annotated multimedia recordings of their surroundings which can be shared with and commented on by peers in online networks. The greater the overall level of mobility, the more fully the affordances of mobile technologies for learning are likely to be exploited, and the more closely their use is likely to align with contemporary pedagogical approaches, hence the importance of the criterion of mobility within Category 1 (see the framework below).

Category 2: General pedagogical approaches. As noted earlier, most MALL resources remain pedagogically very traditional, which leads Burston (2014) to comment: "MALL has yet to realize its full potential and ... achieving this aim is more a matter of pedagogy than technology" (p.344). In light of this, it is vital to consider how MALL learning design relates to established pedagogical approaches, both general and L2-specific.

Over more than a century, but particularly over the last 30-40 years, we have seen a move away from traditional pedagogical approaches based on information transmission and behaviourism towards progressive approaches such as social constructivism (see Burston, 2014, as a MALL reference) and its many offshoots, like inquiry-based learning and task-based learning. These are based on the notion that individuals construct their understanding of the world by integrating new knowledge with existing knowledge as they engage in learning experiences and learning interactions with others. While this does not mean that there is no place in education for information transmission or behaviourist learning - notably for foundational content at lower levels, such as the vocabulary or grammar typically covered in drills and simple games - there is now a widespread recognition that this cannot be the whole picture of learning. At the progressive end of the spectrum, there is much more room for the kinds of active, collaborative learning that we know to be effective. There is also room for a range of recently emerging sociocultural approaches to learning, many of which sit comfortably with social constructivism (Pegrum, 2014). These include situated learning, which involves learning in real-world contexts (see Comas-Quinn, Mardomingo \& Valentine, 2009, as a MALL reference); embodied learning, which involves taking into account the connection between the mind, the body and the wider environment (see Driver, 2012, as a MALL reference); informal learning (see Chen, 2013, as a MALL reference); and of course student-centred learning (see Burston, 2014, as a MALL reference). In addition, at this end of the spectrum there is room to incorporate a focus on the $21^{\text {st }}$ century skills that are now regarded as increasingly essential (Gee, 2013; Mishra \& Kereluik, 2011; NCTE, 2013; P21, n.d.): first and foremost, these are generally seen to include creativity and innovation, linked to entrepreneurship (Barber et al., 2012; Khan, 2012; Robinson, 2011; So, 2012; Zhao, 2012), along with critical thinking and problem-solving, collaboration and teamwork, and autonomy and flexibility (Pegrum, 2014). Naturally, there is some overlap between progressive pedagogical approaches and $21^{\text {st }}$ century skills approaches, and indeed between individual approaches and skills within these categories.

Category 3: L2 pedagogical approaches. There are a number of recent L2 pedagogical approaches which are widely regarded as particularly effective in the teaching of languages. They generally sit comfortably with social constructivism and other progressive approaches, of which they are sometimes a more specific inflection, and they generally sit comfortably with each other. The communicative approach represents a move towards authentic, situated interaction in line with SLA principles (see Category 4 below) (see Pegrum, 2014, as a MALL reference). The task-based approach focuses on situated meaning and the achievement of real-life goals, and technology has been shown to be a good potential fit to enable its 
implementation (see Thomas \& Reinders, 2011, as a MALL reference). An intercultural (communicative) competence approach or intercultural literacy approach goes beyond simply learning about other cultures (or cultural learning) and focuses on situated intercultural interactions (see Palfreyman, 2012, as a MALL reference).

Category 4: SLA principles. SLA research over many years has identified a number of core principles as essential to language learning. These include comprehensible input, comprehensible output, negotiation of meaning in interaction, and noticing of new language, the last of which can be promoted through corrective feedback (e.g., Ellis, 2005). Kukulska-Hulme and Bull (2009) have linked MALL to noticing, while Burston (2014) points out that in the design of at least one MALL project, constructivism has been directly linked to noticing. Many MALL projects and resources capitalize on the ability of mobile devices, which at their most sophisticated can track our learning in real-world contexts, to provide a wide range of detailed, automated feedback, which can and should be complemented by human feedback (Pegrum, 2014). Progressive pedagogical approaches and their specific L2 inflections can be employed in such a way as to make room for all of the above SLA principles. These principles are often foregrounded in combination in the MALL literature (e.g., Blake, 2008; Holden \& Sykes, 2012; Nah et al., 2008; Potter, 2011; Reinders \& Wattana, 2012).

Category 5: Affective principles. It is widely accepted that affective factors play an important role in language learning. Teachers have explored many strategies for increasing students' engagement and motivation through the use of interesting, relevant resources (Beres, 2011) and lowering their affective filters (see Edge, Searle, Chiu, Zhao \& Landay, 2011).

Mobile design guidelines developed over recent years have taken many of the learning affordances and pedagogical possibilities of mobile devices into account in varying combinations (e.g., Herrington, Herrington \& Mantei, 2009; Sharples et al., 2009). Our own framework, outlined below, has a slightly different aim as it focuses on evaluation rather than design, but it nevertheless details a set of principles which could be considered in the design phase of mobile resources.

\section{The Framework}

Based on the foregoing analysis of affordances, pedagogies and principles, we have developed a framework for evaluating the learning design of mobile resources for language teaching and learning, whether those resources are mobile materials like websites or apps, or collections of websites or apps, or mobile activities designed around websites or apps. It is important to evaluate a mobile resource at the macro level; that is, while a website or app used alone may be evaluated in isolation, a collection should be evaluated at the level of the whole collection, and an activity incorporating one or more websites or apps should be evaluated at the level of the whole activity.

The evaluation framework consists of five different categories, subdivided into criteria which may be rated on a continuum from 1-5 (with the exception of two criteria with higher scores, in Categories 1 and 2 respectively, as explained in the table notes), resulting in a total score for each criterion, each category, and the mobile resource as a whole. Brief explanations of each criterion are given under 'Evaluating MALL resources' above. Of course, this is necessarily an inexact science, with educators being required to estimate scores on the various continua to achieve a total. Absolute scores are not important in themselves, but where two or more resources are compared, the resource with a higher 
score is likely to be the one with more sophisticated pedagogical potential. Continua or even categories considered irrelevant may be omitted, but the act of evaluating a resource against multiple criteria and categories may encourage practitioners to exploit mobile resources - or design activities - so as to improve them in as yet unconsidered ways.

\section{Criteria}

Evaluation Continuum
Score

\section{Category 1: Educational Affordances exploited in Learning Design (_/50)}

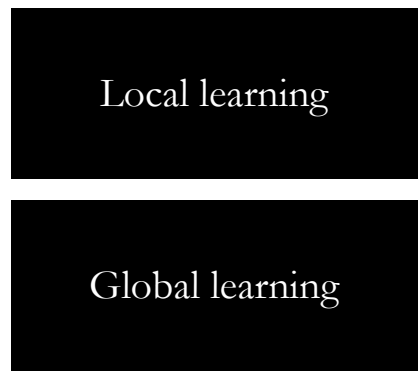

1

2

3

4

5

little potential for local learning $\Leftrightarrow$ much potential for local learning

\begin{tabular}{l|l|l|l|l|l|}
1 & 2 & 3 & 4 & 5
\end{tabular}

little potential for global learning $\Leftrightarrow$ much potential for global learning

\begin{tabular}{l|l|l|l|l|l|}
1 & 2 & 3 & 4 & 5
\end{tabular}

Episodic learning

little potential for episodic learning $\Leftrightarrow$ much potential for episodic learning

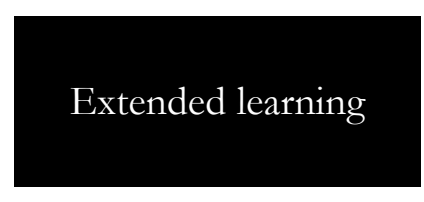

\begin{tabular}{l|l|l|l|l|l|}
1 & 2 & 3 & 4 & 5
\end{tabular}

little potential for extended learning $\Leftrightarrow$ much potential for extended learning

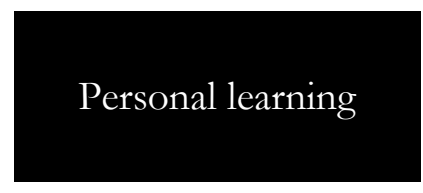

\begin{tabular}{l|l|l|l|l|l|}
1 & 2 & 3 & 4 & 5
\end{tabular}

little potential for personal learning $\Leftrightarrow$ much potential for personal learning

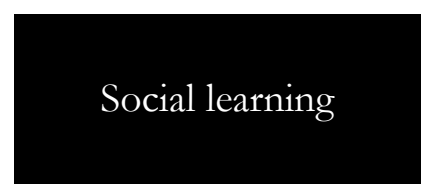

$$
1
$$

2

3

4

5

little potential for social learning $\Leftrightarrow$ much potential for social learning

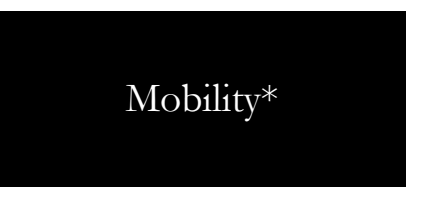

12

15

20

devices mobile $\Leftrightarrow$ devices \& students mobile $\Leftrightarrow$ devices, students \& learning experience mobile

* Note: it is suggested that this criterion should be scored more bighly than the others in this category, since it is arguably the most important, as explained under 'Evaluating MALL resources' above.

\section{Category 2: General Pedagogical Design}

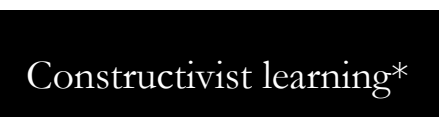

$$
2
$$

behaviourist learning $\Leftrightarrow$ social constructivist learning

4

6

8

10 


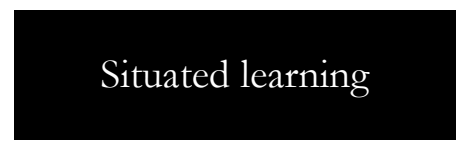

Embodied learning

Informal learning

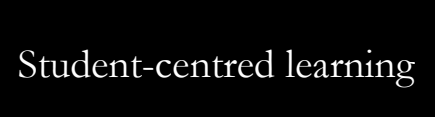

21C skills: Creative learning

21C skills: Critical learning

21C skills: Collaborative learning

21C skills: Autonomous learning

\begin{tabular}{|c|c|c|c|c|}
\hline 1 & 2 & 3 & 4 & 5 \\
\hline & abstract learning & $\Leftrightarrow$ & situated learning & \\
\hline 1 & 2 & 3 & 4 & 5 \\
\hline \multicolumn{4}{|c|}{ disembodied learning $\Leftrightarrow$ embodied learning } \\
\hline
\end{tabular}

\begin{tabular}{l|l|l|l|l|l|}
1 & 2 & 3 & 4 & 5
\end{tabular}

little informal learning $\Leftrightarrow$ much informal learning (may be alongside formal learning)

\begin{tabular}{|l|l|l|l|l|l|}
\hline 1 & 2 & 3 & 4 & 5
\end{tabular}

teacher-centred learning $\Leftrightarrow$ student-centred learning

\begin{tabular}{l|l|l|l|l|l|}
1 & 2 & 3 & 4 & 5
\end{tabular}

uncreative learning $\Leftrightarrow$ highly creative learning

\begin{tabular}{l|l|l|l|l|l|}
1 & 2 & 3 & 4 & 5
\end{tabular}

uncritical learning $\Leftrightarrow$ critical learning

\begin{tabular}{l|l|l|l|l|l|}
1 & 2 & 3 & 4 & 5
\end{tabular}

uncollaborative learning $\Leftrightarrow$ collaborative learning

\begin{tabular}{|l|l|l|l|l|l|}
1 & 2 & 3 & 4 & 5
\end{tabular}

student dependency $\Leftrightarrow$ student autonomy

* Note: it is suggested that this criterion should be scored more highly than the others in this category, since it is arguably the most important pedagogical approach and in some senses opens up the potential for many of the others, as explained under 'Evaluating MALL resources' above.

Category 3: L2 Pedagogical Design

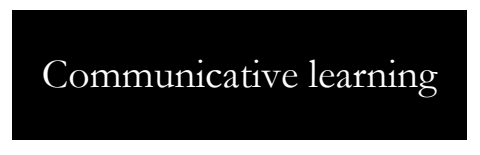

1

2

3

4

5

non-communicative learning $\Leftrightarrow$ communicative learning

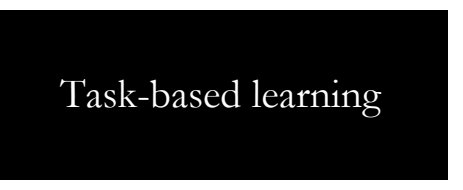

\begin{tabular}{|l|l|l|l|l|l|}
\hline 1 & 2 & 3 & 4 & 5 \\
\hline
\end{tabular}

no meaning-based task focus $\Leftrightarrow$ meaning-based task focus

(Inter-)cultural learning

\begin{tabular}{|l|l|l|l|l|}
\hline 1 & 2 & 3 & 4 & 5
\end{tabular}

no cultural element $\Leftrightarrow$ cultural learning $\Leftrightarrow$ intercultural learning 


\section{Category 4: SLA Design (_/25)}

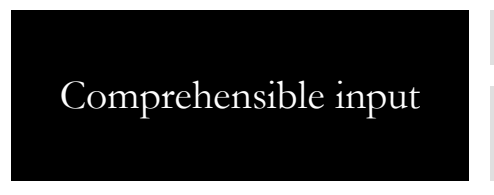

1

2

3

4

5

little comprehensible input $\Leftrightarrow$ much comprehensible input

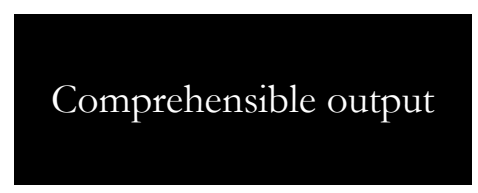

1

2

3

4

5

little comprehensible output $\Leftrightarrow$ much comprehensible output

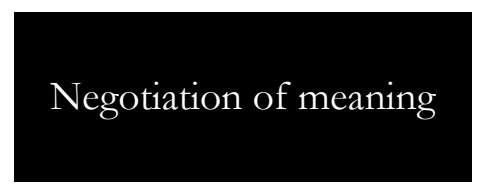

1

2

3

4

5

little negotiation of meaning $\Leftrightarrow$ much negotiation of meaning

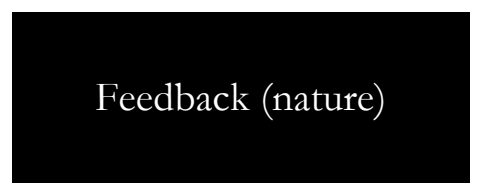

\begin{tabular}{|l|l|l|l|l|l|}
\hline 1 & 2 & 3 & 4 & 5
\end{tabular}

automated feedback $\Leftrightarrow$ human feedback $\Leftrightarrow$ automated \& human feedback

Feedback (detail)

\begin{tabular}{l|c|c|c|c}
1 & 2 & 3 & 4 & 5 \\
& limited feedback $\Leftrightarrow$ detailed feedback
\end{tabular}

\section{Category 5: Affective Design (_/10)}
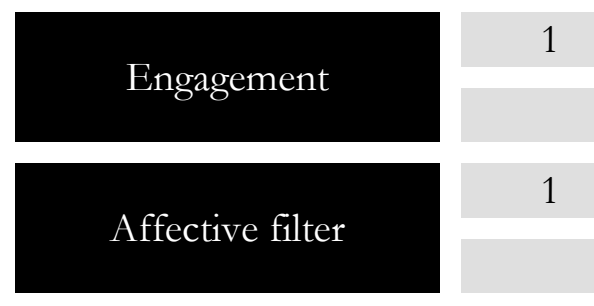

(10)

\begin{tabular}{|c|c|c|c|c|}
\hline \multicolumn{5}{|c|}{ unengaging $\Leftrightarrow$ highly engaging } \\
\hline 1 & 2 & 3 & 4 & 5 \\
\hline
\end{tabular}

\section{Total}

Overall score out of maximum 150 points

\section{Applying the framework}

Although many MALL materials are relatively cheap to purchase (think of the many apps for sale for no more than a couple of US dollars) or freely available (such as AR browsers), their implementation can require a significant investment of time and energy. With the potential for linking formal in-class learning with informal out-of-class learning, emphasising situated learning, and enhancing learner autonomy - to name only some of the possible benefits - teachers may need to accommodate to new ways of teaching and supporting learning, and to acquire or the necessary accompanying technical skills.

For this reason, it is important to weigh the benefits of adoption against the possible investment of time and resources. This includes the pedagogical benefits as outlined in our framework above, but it may 
also be important to consider the practical or 'organisational' affordances of MALL resources, as outlined by Reinders \& White (2010). These include, for example, the extent to which the resources improve access to learning opportunities, especially for learners who otherwise have little or no such access (e.g., learners in developing contexts, rural learners, disabled learners, or even learners with busy job and family schedules). Other organisational benefits include the possibility of learners communicating with peers outside formal institutional settings and teachers monitoring students' engagement with learning opportunities (e.g., through recording completion of MALL modules).

As with any evaluation, the above framework can be applied before, during and after use of the resources (Breen, 1989). When a decision is made to use MALL resources, it is in fact essential to evaluate them not only prior to use but during and after their use, as "long-term, systematic evaluations of materials ... are generally considered to be successful" (Tomlinson, 1998, p.5). These evaluations include "formative decisions for improvement through supplementation or adaptation and [sensitising] teachers to their own teaching and learning situation" (Nedkova, 2000, p.210). With MALL resources, which are likely to be new to many teachers, such evaluations are important in identifying potential and actual obstacles to use, and establishing professional development needs. These can also be uncovered through post-use evaluations that, in the case of MALL, can be particularly helpful in bringing to light technical issues, such as a lack of wireless coverage, privacy issues (Blyth, 2014), and institutional issues, such as a lack of clear policies on the use of mobile devices in class. Such evaluations can of course also include the learners (Masaharu, 1998) and their experiences with the resources. 


\section{MALL evaluation - an example of a 'virtual campus tour' activity}

Description: in this activity, students at a university in Thailand create a virtual campus tour for foreign visitors. Students use augmented reality to annotate physical objects (buildings, natural features) with historical and practical information to help visitors navigate the campus. Working in teams, they leave both written and audio comments that are specific to each site.

Educational affordances: $41 / 50$

The activity offers high affordances for local and global learning, mobility and social learning and somewhat less so for personal, episodic and extended learning, due to the fact that the activity is only carried out once, without follow-up.

General pedagogical design: $37 / 50$

The activity is constructivist and situated in nature, and encourages collaborative learning. Although it involves some embodied, informal, student-centred, creative, critical and autonomous learning, these are not its primary focus.

Pedagogical design: $12 / 15$

The activity is communicative in nature, involves carrying out a task, and encourages students to consider the intercultural element in the production of their tour.

SLA design: $15 / 25$

Opportunities for comprehensible input, output and negotiation of meaning are limited to the interaction among the students. Feedback is implicit in that it can only be measured by the target users' experience of taking the tour.

Affective design: 9/10

The activity is new for the students and involves using English for real-life purposes, something that many will not be used to.

Total score: $111 / 150$

Practical comments: the activity requires smartphones, but these can be shared among students ( 1 per 4 ) and internet connectivity. They also require students, and their teacher, to know how to use an augmented reality app. Some pre-teaching may be required. The skills that students develop will be transferable.

\section{Conclusion}

We hope to have shown that MALL carries the potential to enhance language teaching and learning in line with recent pedagogical thinking and SLA research, and that this potential can be identified and approximately quantified when deciding whether to adopt, adapt or reject MALL resources in particular 
teaching contexts. The framework we have introduced above foregrounds educational affordances, general pedagogical approaches, L2 pedagogical approaches, SLA principles, and affective factors. While primarily designed for evaluation, the principles in our framework could also be used to guide the development of mobile materials and mobile activities. On the other hand, although our framework covers many pedagogical elements, it does not include any measurement of learning outcomes, which should be considered after initial implementation. Moreover, while our framework focuses on pedagogical evaluation, organisational affordances also need to be considered. Through a consistent, wide-ranging approach to evaluation, ideally in each of the pre-, during- and post-implementation phases, our understanding of the ways in which MALL resources can support the language teaching and learning process will be greatly enhanced.

\section{References}

Barber, M., Donnelly, K., \& Rizvi, S. (2012). Oceans of innovation: The Atlantic, the Pacific, global leadership and the future of education. London: IPPR. http://www.ippr.org/images/media/files/publication/2012/09/oceans-ofinnovation_Aug2012_9543.pdf

Beatty, K. (2013). Beyond the classroom: Mobile learning in the wider world. The International Research Foundation for English Language Education. http:/ /www.tirfonline.org/english-in-the-

workforce/mobile-assisted-language-learning/beyond-the-classroom-mobile-learning-the-widerworld/

Beres, D. (2011). Mobile-Assisted Language Learning from the Student Perspective: Encouraging Effective Language Learning Strategies Outside of the Classroom." Academic Podcasting and Mobile Assisted Language Learning: Applications and Outcomes. Hershey: IGI Global, 93-110.

Blake, R.J. (2008). Brave new digital classroom: Technology and foreign language learning. Washington, DC: Georgetown University Press.

Blodget, H., et al. (2013).

Branden, K. van den, Bygate, M. \& Norris, J. M. (Eds.) (2009). Task-based Language Teaching: A Reader. Amsterdam: John Benjamins.

Breen, M. (1989) 'The evaluation cycle for language learning tasks' in P. Rea-Dickins and K. Germaine (eds). Evaluation. Oxford: Oxford University Press.

Burston, J. (2013). Mobile-assisted language learning : a selected annotated bibliography of implementation studies 1994 - 2012. Language Learning \& Technology, 17(3), 157-225.

Burston, J. (2014). MALL: The pedagogical challenges. Computer Assisted Language Learning, 27(4), 344357.

Chen, X-B. (2013). Tablets for informal language learning: Student usage and attitudes. Language Learning \& Technology, 17(1), 20-36.

Comas-Quinn, A., Mardomingo, R., \& Valentine, C. (2009). Mobile blogs in language learning: Making the most of informal and situated learning opportunities. ReCALL, 21(1), 96-112.

Coyle, D., Hood, P., \& Marsh, D. (2010). CLIL: Content and Language Integrated Learning. Cambridge: Cambridge University Press.

Dennen, V., \& Hao, S. (2014). Paradigms of use, learning theory, and app design. In C. Miller \& A. Doering (Eds.), The new landscape of mobile learning: Redesigning education in an app-based world. New York: Routledge.

Driver, P. (2012). Pervasive games and mobile technologies for embodied language learning. International Journal of Computer-Assisted Language Learning and Teaching, 2(4), 50-63. 
The Economist. (2012, November 21). Live and unplugged.

http://www.economist.com/news/21566417-2013-internet-will-become-mostly-mobilemedium-who-will-be-winners-and-losers-live-and

Edge, D., Searle, E., Chiu, K., Zhao, J., Landay, J. (20110. MicroMandarin: Mobile Language Learning in Context. In: Proceedings of CHI 2011, pp. 3169-3178.

Ellis, R. (2005). Principles of instructed language learning. Asian EFL Journal Quarterly, 7(3), 9-24. http://www.asian-efl-journal.com/September_2005_EBook_editions.pdf

Garcia, A. (Ed.). (2014). Teacher agency and connected learning. In C. Garcia (Ed.), Teaching in the connected learning classroom (pp.6-9). Irvine, CA: Digital Media and Learning Research Hub. http://dmlhub.net/publications/teaching-connected-learning-classroom

Gee, J.P. (2013). The anti-education era: Creating smarter students through digital learning. New York: Palgrave Macmillan.

Herrington, A., Herrington, J., \& Mantei, J. (2009). Design principles for mobile learning. In J. Herrington, A. Herrington, J. Mantei, I. Olney \& B. (Eds.), New technologies, new pedagogies: Mobile learning in higher education (pp.129-138). Faculty of Education, University of

Wollongong.University of Wollongong Research Online: Faculty of Education - Papers. http://ro.uow.edu.au/edupapers/88

Hockly, N. (2013). Designer learning: The teacher as designer of mobile-based classroom learning experiences. The International Research Foundation for English Language Education. http:/ /www.tirfonline.org/english-in-the-workforce/mobile-assisted-languagelearning/designer-learning-the-teacher-as-designer-of-mobile-based-classroom-learningexperiences/

Khan, S. (2012). The one world schoolhouse: Education reimagined. London: Hodder \& Stoughton.

Klopfer, E., \& Squire, K. (2008). Environmental Detectives: the development of an augmented reality platform for environmental simulations. Educational Technology Research and Development, 56(2), 203-228.

Kukulska-Hulme, A., \& Bull, S. (2009). Theory-based support for mobile language learning: Noticing and recording. International Journal of Interactive Mobile Technologies, 3(2), 12-18.

Lave, J., \& Wenger, E. (1991). Situated learning: Legitimate peripheral participation. Cambridge: Cambridge University Press.

Masaharu, H. 1998. What do teachers really want from coursebooks?” in B. Tomlinson (ed.) Materials development in language teaching. Cambridge: Cambridge University Press.

Meeker, M., \& Wu, L. (2014, May 28). Internet trends 2014 - Code Conference. http://www.kpcb.com/internet-trends

Miller, C., \& Doering, A. (Eds.). (2014). The new landscape of mobile learning: Redesigning education in an appbased world. New York: Routledge.

Mishra, P., \& Kereluik, K. (2011). What is $21^{\text {st }}$ century learning? A review and synthesis. Presented at SITE 2011, Nashville, USA, March 7-11. http://punya.educ.msu.edu/presentations/site2011/SITE_2011_21st_Century.pdf

Murray, O.T., \& Olcese, N.R. (2011, November/December). Teaching and learning with iPads, ready or not? TechTrends, 55(6), 42-48.

Nah, K.C., White, P., \& Sussex, R. (2008). The potential of using a mobile phone to access the internet for learning EFL listening skills within a Korean context. ReCALL, 20(3), 331-347.

NCTE. (2013). The NCTE definition of $21^{\text {st }}$ century literacies. Position statement. [Adopted February 15, 2008; updated February, 2013.] http://www.ncte.org/positions/statements/21 stcentdefinition 
Nedkova, M. 2000. 'Evaluation' in Michael Byram (ed). Routledge encyclopedia of language teaching and learning. London and New York: Routledge.

Oakley, G., Pegrum, M., Faulkner, R., \& Striepe, M. (2012). Exploring the pedagogical applications of mobile technologies for teaching literacy. Report for the Association of Independent Schools of Western

Australia. http://www.education.uwa.edu.au/research/?a=2195652

P21 (Partnership for $21^{\text {st }}$ Century Skills) [USA]. (n.d.). Framework for $21^{\text {st }}$ century learning. http://www.p21.org/overview/skills-framework

Palfreyman, D.M. (2012). Bringing the world into the institution: Mobile intercultural learning for staff and students. In J.E. Díaz-Vera (Ed.), Left to my own devices: Learner autonomy and mobile-assisted language learning (pp.163-181). Bingley, West Yorkshire: Emerald Group.

Pegrum, M. (2014). Mobile learning: Languages, literacies and cultures. Basingstoke: Palgrave Macmillan.

Phillips, R., McNaught, C., \& Kennedy, G. (2012). Evaluating e-learning: Guiding research and practice. New York: Routledge.

Puentedura, R. (2012). Building upon SAMR. Presented at Presbyterian Ladies' College, Perth, Australia, September 14.

Quitney Anderson, J., \& Rainie, L. (2012). The web is dead? ... Washington, DC: Pew Internet. http://pewinternet.org/ /media//Files/Reports/2012/PIP_Future_of_Apps_and_Web.pdf

Reinders, H., Lakarnchua, O. \& Pegrum, M. (2014). A trade-off in learning: Mobile augmented reality for language learning. In M. Thomas \& H. Reinders (Eds.), Task-based language teaching in Asia. London: Bloomsbury.

Reinders, H., \& Wattana, S. (2012). Talk to me! Games and students' willingness to communicate. In H. Reinders (Ed.), Digital games in language learning and teaching (pp.156-188). Basingstoke, Hampshire: Palgrave Macmillan.

Reinders, H. \& C. White 2010 'The theory and practice of technology in materials development and task design'. In: Harwood, N. Materials in ELT: Theory and Practice (p. 58-80). Cambridge: Cambridge University Press.

Robinson, K. (2011). Out of our minds: Learning to be creative. (Revised ed.). Chichester: Capstone.

Searson, M. (2014). Foreword: The failure of education's first mobile device. In C. Miller \& A. Doering (Eds.), The new landscape of mobile learning: Redesigning education in an app-based world. New York: Routledge.

Segal, A. (2011) Do Gestural Interfaces Promote Thinking? Embodied Interaction: Congruent Gestures and Direct Touch Promote Performance in Math. Unpublished PhD thesis, Columbia University.

Sharples, M., Arnedillo-Sánchez, I., Milrad, M., \& Vavoula, G. (2009). Mobile learning: Small devices, big issues. In N. Balacheff, S. Ludvigsen, T. de Jong, A. Lazonder, S. Barnes, \& L. Montandon (Eds.), Technology enhanced learning: Principles and products (pp. 233- 249). Berlin: Springer.

So, H.-J. (2012). Turning on mobile learning in Asia: Illustrative initiatives and policy implications. Paris:

UNESCO. http://unesdoc.unesco.org/images/0021/002162/216283E.pdf

Thomas, M. \& Reiders, H. (2011). Task-Based Language Teaching and Technology. New York: Continuum.

Tomlinson, B. ed. 1998. Materials development in language teaching. Cambridge: Cambridge University Press.

UNESCO (United Nations Educational, Scientific and Cultural Organization). (2012). Youth and skills: Putting education to work. Paris: UNESCO. http://unesdoc.unesco.org/images/0021/002180/218003e.pdf

Zhao, Y. (2012). World class learners: Educating creative and entrepreneurial students. Thousand Oaks, CA: Corwin. 